\title{
Inflatable pressure garment device for pressure therapy after chest wall keloid operation and radiotherapy
}

\author{
Shu Liu ${ }^{1 *}$, Ke-Xin Song ${ }^{2 *}$, You-Bin Wang ${ }^{2}$ \\ ${ }^{\prime}$ China Meitan General Hospital Affiliated to North China University of Science and Technology, Beijing 100028, China. \\ ${ }^{2}$ Department of Plastic Surgery, Peking Union Medical College Hospital, Beijing 100032, China. \\ *Authors contributed equally.
}

Correspondence to: Dr. You-Bin Wang. Department of Plastic Surgery, Peking Union Medical College Hospital, Beijing 100032, China.

E-mail: wybenz@sina.com

How to cite this article: Liu S, Song KX, Wang YB. Inflatable pressure garment device for pressure therapy after chest wall keloid operation and radiotherapy. Plast Aesthet Res 2017;4:92-6.

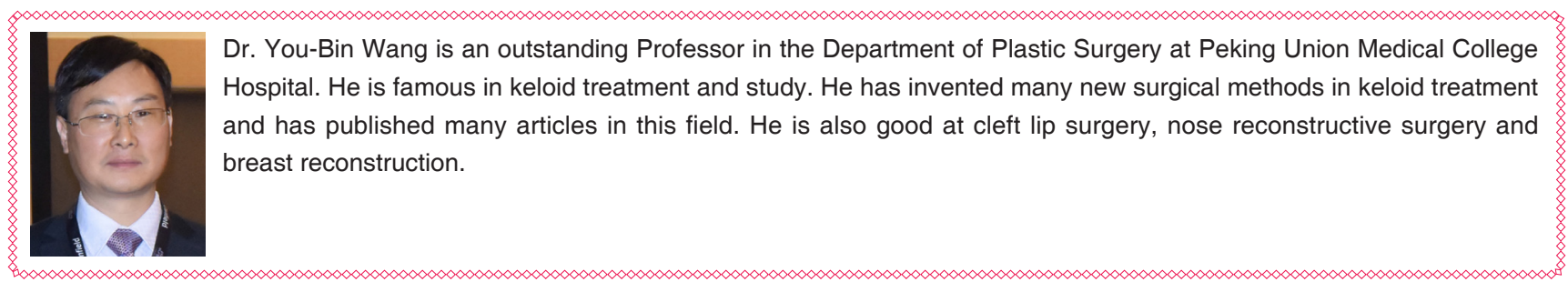

Article history:

Received: 21-03-2017

Accepted: 04-05-2017

Published: 16-06-2017

\section{Key words:}

Chest wall keloid,

inflatable pressure garment device, pressure therapy

This is an open access article distributed under the terms of the Creative Commons AttributionNonCommercial-ShareAlike 3.0 License, which allows others to remix, tweak, and build upon the work non-commercially, as long as the author is credited and the new creations are licensed under the identical terms.
ABSTRACT

Aim: Keloids often occur on the chest wall, with high recurrence rates despite surgery and radiotherapy. Garment pressure therapy is commonly used to treat hypertrophic scars and keloids. Irregularity of the chest wall surface can inhibit the effects of the garment pressure therapy. This clinical study is to determine the effect of inflatable pressure garment in preventing keloid recurrence after keloid operation and radiotherapy. Methods: Chest wall keloid was removed and radiotherapy was administered at the surgical sites on the 1st and 7th postoperative days in 61 patients. An inflatable pressure garment device was designed and its pressure effect was confirmed by comparing it with the general pressure garment at the sites of the right and left infraclavicular area, manubrium and sternal area between breasts. The keloid patients were treated with inflatable pressure garment device 1 month after the operation. The clinical results were observed. Results: The detected pressures were $0.26 \pm 0.21,0.49 \pm 0.16,0.53 \pm 0.10$ and $0.91 \pm 0.17 \mathrm{kPa}$ at the sites of the right infraclavicular area, the manubrium area, the left infraclavicular area and sternal area between breasts with the general pressure garment. These were obvious lower $(P<0.05)$ than that generated with the inflatable pressure garment device of which the average pressures were 7.26 $\pm 0.41,7.6 \pm 0.32,9.02 \pm 0.54$ and $10.31 \pm 0.14 \mathrm{kPa}$ at the corresponding sites. Sixty-one patients were treated with this device after keloid surgical excision and radiotherapy. Satisfactory results were observed. Conclusion: Appropriate and effective pressure can be generated with inflatable pressure garment on the chest wall. This device may be useful in preventing chest wall keloid recurrence after keloid operation and radiotherapy.

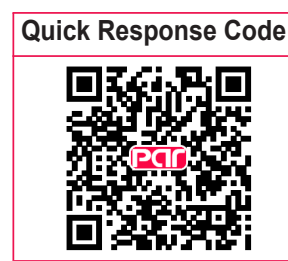




\section{INTRODUCTION}

Keloids may be induced by many causes, such as acne, folliculitis, insect bites or surgery. ${ }^{[1]}$ Keloids often occur on the chest wall. Many therapeutic approaches for keloids have been reported in the literature. The most commonly accepted treatments include excision, irradiation, steroid injections, and pressure therapy with silicone gel sheets or bandages. ${ }^{[2]}$

Keloids are likely to recur, which complicates their treatment. The reported keloid recurrence rate varies depending on the treatment method. ${ }^{[3]}$ In the chest wall, the reported keloid recurrence rate ranges from $9.7 \%$ to $43.1 \%$ for patients treated with surgical excision and postoperative radiation. ${ }^{[4,5]}$ Recurrent keloids often spread faster and become larger; it is therefore necessary to identify a method to prevent keloid recurrence.

Pressure therapy is effective in treating hypertrophic scars, especially scars on the ear ${ }^{[6]}$ or body. ${ }^{[7]}$ Pressure garments are often used in body scar pressure therapy. During treatment, a pressure garment is placed over the scar and is effective when appropriate pressure is applied to the scar surface. However, the pressures that can be generated at different anatomical sites differ significantly, and lower pressures generally are less effective. Due to the larger radius of the chest, pressure garments usually generate low pressures in this area, and pressures are even lower in concave areas, such as the mid-sternum. ${ }^{[8]}$ To solve this problem, we designed an inflatable pressure garment device.

\section{METHODS}

\section{Surgical methods}

The edge of the keloid was marked with gentian violet; then, $0.5 \%$ lidocaine was infiltrated to provide local anesthesia in the skin around the keloid. A fullthickness incision was made along the mark, and the keloid was removed. After achieving hemostasis, the skin around the incisional border was undermined at the deep layer of the superficial fascia for $3-5 \mathrm{~cm}$, and the incision was closed. A skin graft was used if the wound was too wide to be closed primarily. The wound was then covered with sterile gauze. Radiation therapy was administered. The sutures were removed 14 to 21 days after the operation.

\section{Radiotherapy methods}

Radiotherapy was administered at the surgical sites (closed primarily) on the 1st and 7th postoperative days. Every surgical site was treated with $900 \mathrm{cGy}$ of electron beam irradiation at each session. A second radiotherapy session was administered on the 14th postoperative day if skin graft was used, when survival of the skin graft had been established and the sutures had been removed.

\section{Comparative study of inflatable pressure} garment device and general pressure garment In order to confirm the pressure effect of the inflatable pressure garment device, a comparative study was conducted between the device and the regular pressure garment. The device consisted of 3 parts: a regular pressure garment, an inflatable silicon expander and an inflation device. Ten volunteer young patients $(5$ male and 5 female, age range between 21 and 30 years) wore the regular pressure garment (WSY003 Short Sleeve Garment, Beijing Medical Elastic Sleeve) first. Pressure was detected and recorded using a manometer (COMARK C9553, England) at the sites of the right and left infraclavicular area, manubrium and mid-sternum area between breasts. Then the inflatable silicon expander was inserted under the garment at the same area and was inflated until the patients felt slight pain at the sites. The pressure was then detected and recorded. The data was analyzed with SPSS 22.0 (SPSS Inc., Chicago, IL, USA) using the t-test. All data are reported as the mean \pm standard error of the mean. The level of the test was considered statistically significant if less than 0.05 .

\section{Pressure therapy with an inflatable pressure garment device}

The inflatable pressure garment device was used 1 month after the operation to allow for appropriate wound healing. First, the wound site was cleaned with warm water. A piece of silicon gel was applied to the wound after the site was dry. Then, the patient was asked to wear a regular pressure garment [Figure $1 \mathrm{~A}]$. Afterwards, the silicon expander, which was wrapped with soft cloth, was inserted under the garment. The expander was carefully adjusted to ensure that it covered the entire area of the scar. The inflation device
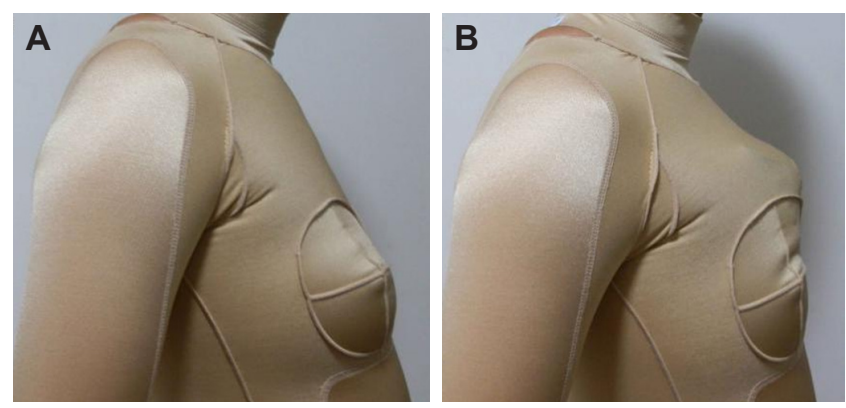

Figure 1: The concave site became convex after the expander was inflated. (A) The conventional pressure garment; (B) the inflatable pressure garment 

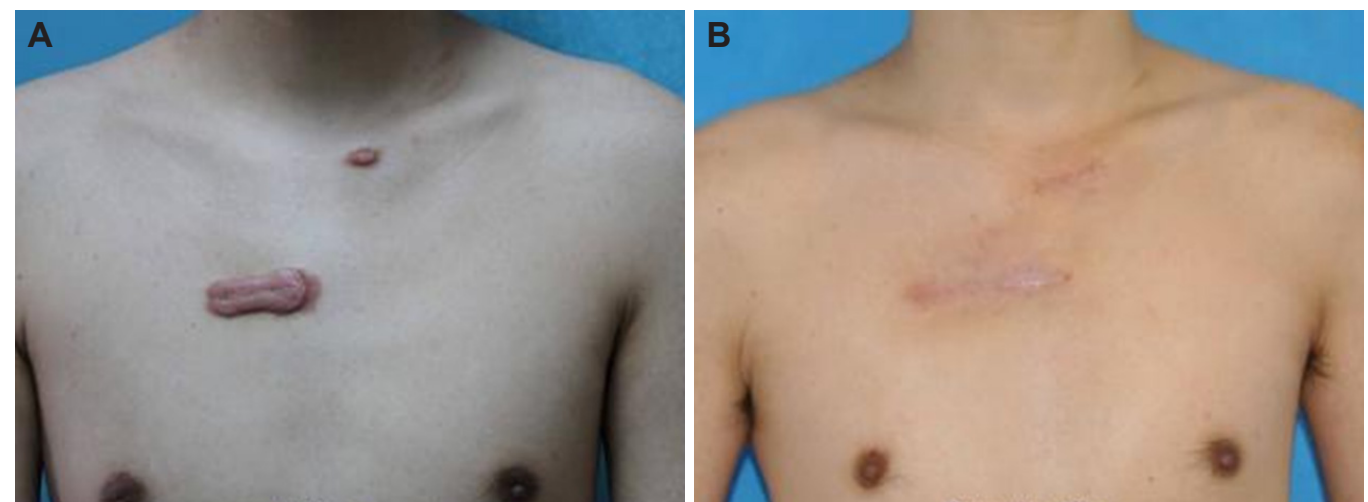

Figure 2: A male patient with a chest wall keloid that was treated with surgical excision, radiotherapy and inflatable garment pressure therapy. (A) Preoperative view; (B) 8 months after the operation, the incision scar was flat, pale, smooth and almost invisible
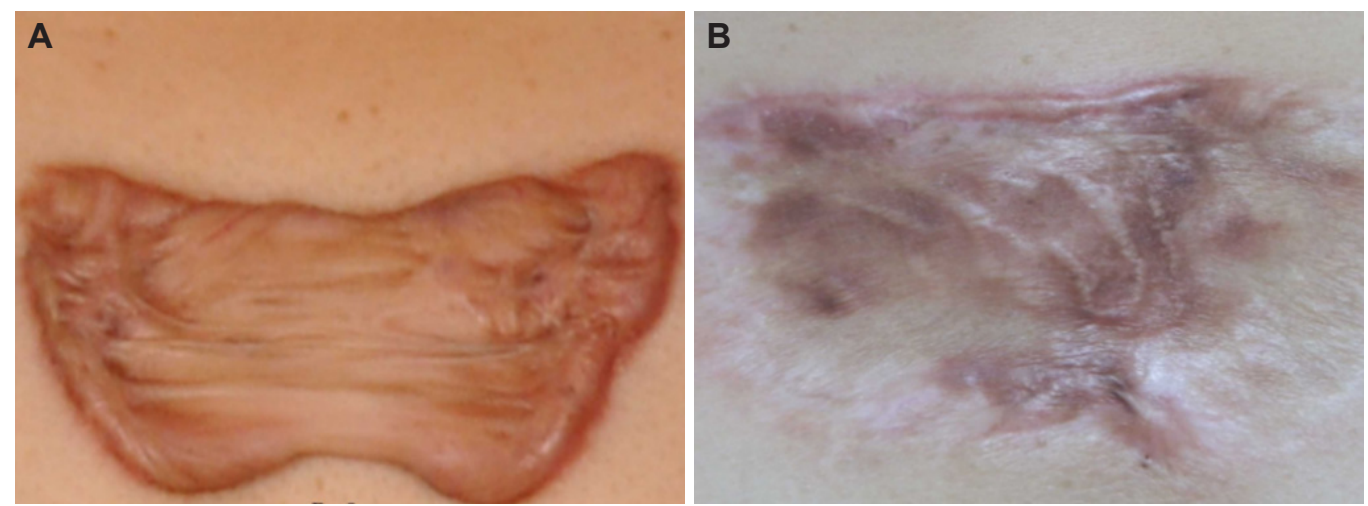

Figure 3: A female patient with chest wall keloid that were treated with surgical excision, skin graft, radiotherapy and the inflatable garment pressure device therapy. (A) Preoperative view; (B) almost all of the incision was flat and pale 18 months after surgery

was used to inflate the expander, generating pressure [Figure 1B]. As more air was added to the expander, the pressure increased. The appropriate pressure range was from 4.5 to $10 \mathrm{kPa}$. Higher pressure may cause pain at the involved site, whereas lower pressure may be less effective. None of the patients reported breathlessness. The patient was able to adjust the pressure by controlling the inflation device; the expander size was chosen based on the size of the scar. Patients were asked to use the inflatable pressure garment device daily for at least $12 \mathrm{~h}$ during the therapy period. Pressure therapy could be stopped after 6 to 12 months of therapy, once the scar had become pale, flat and smooth.

\section{RESULTS}

\section{Pressure generated with the inflatable pressure garment device and the regular pressure garment}

The detected pressures using regular pressure garment were $0.26 \pm 0.21,0.49 \pm 0.16,0.53 \pm 0.10$, and 0.91 $\pm 0.17 \mathrm{kPa}$, at the site of the right infraclavicular area, manubrium area, left infraclavicular area and midsternum area between breasts respectively. Higher pressure was generated after the silicon expander was inserted and inflated. The average pressures were $7.26 \pm 0.41,7.6 \pm 0.32,9.02 \pm 0.54$, and 10.31 $\pm 0.14 \mathrm{kPa}$ at the site of the right infraclavicular area, the manubrium area, the left infraclavicular area and mid-sternum area between breasts respectively. The difference of the recorded pressure effect was obvious at each site between the inflatable pressure garment device and the regular pressure garment $(P<0.05)$.

\section{Clinical effects of the inflatable pressure garment device}

Effective pressure was obtained on the chest wall of the patients. Satisfactory results were observed in patients treated with keloid excision, radiotherapy and inflatable garment device-based pressure therapy. Sixty-one patients were treated with this method between May and October of 2013. The follow-up time was between 6 and 18 months. No recurrences were observed in these patients. The incision scars were flat, pale, smooth and almost invisible at the operation sites in patients without skin graft. The patients were satisfied with the results [Figures 2 and 3]. Some recurrences were observed in patients treated with the regular pressure garment before [Figures 4 and 5]. 


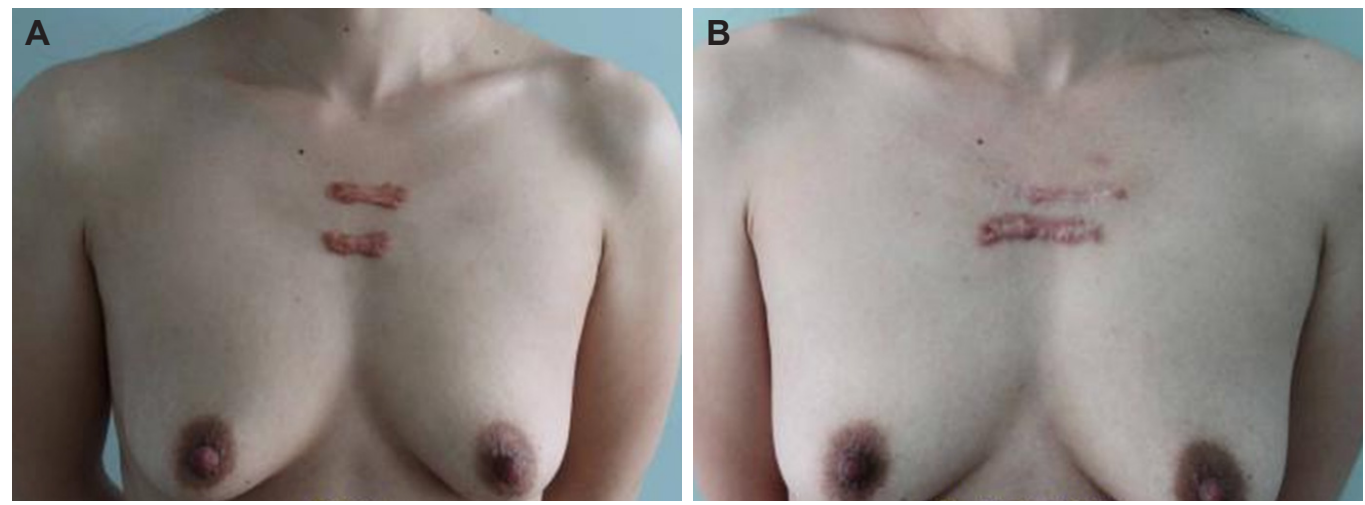

Figure 4: A female patient with chest wall keloids that were treated with surgical excision, radiotherapy and conventional garment pressure therapy. (A) Preoperative view; (B) 21 months after the operation, keloid recurrence was observed
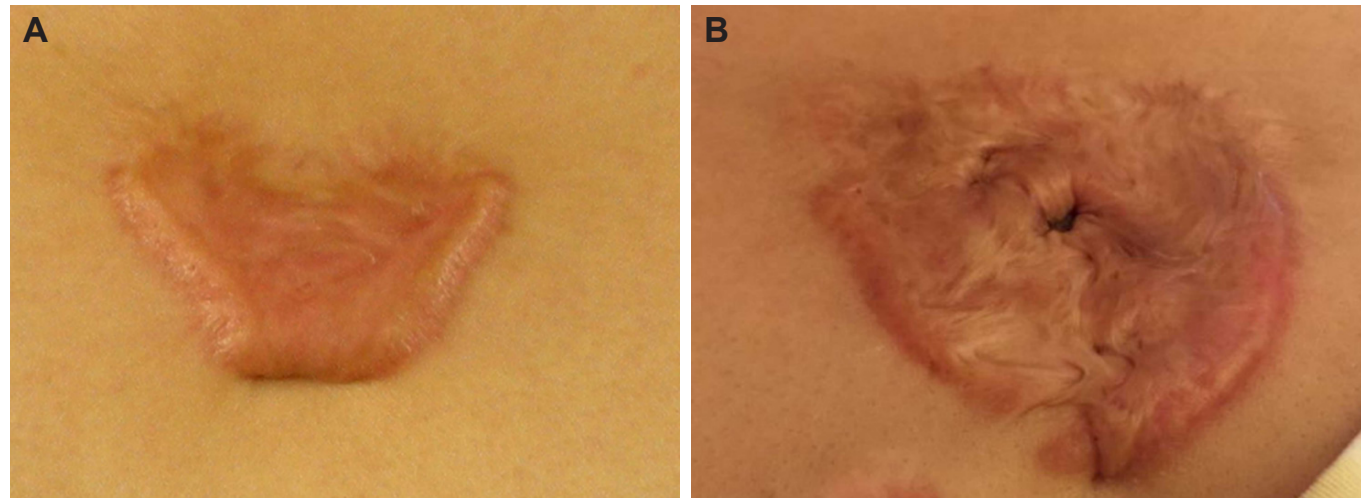

Figure 5: A female patient with chest wall keloid that were treated with surgical excision, skin graft, radiotherapy and conventional garment pressure therapy. (A) Preoperative view; (B) keloid recurrence was observed 3 years after operation

\section{DISCUSSION}

Pressure has been known to be a useful treatment method for scars since the 16th century. ${ }^{\left[{ }^{[}\right]}$Garment pressure therapy is now widely used in the treatment of hypertrophic scars and keloids. Possible mechanisms of its effect include hypoxia, biochemical changes and cellular or collagenous influences. ${ }^{[8]}$ The effects of pressure have also been reported on the growth of human scar fibroblasts and on cellular proliferation and apoptosis. ${ }^{[10,11]}$ Pressure inhibits the proliferation of cells, especially fibroblasts; it also suppresses collagen production and accelerates apoptosis, inhibiting the growth of hypertrophic scars and keloids.

Appropriate pressure levels are required for garment pressure treatment. Van den Kerckhove et al. ${ }^{[7]}$ compared the effects of 10 and $15 \mathrm{mmHg}$ pressure garments. They observed that $15 \mathrm{mmHg}$ of pressure tends to accelerate scar maturation. Some authors have recommended the use of pressures between 20 and $40 \mathrm{mmHg}$, based on the theoretical $25 \mathrm{mmHg}$ arterial capillary pressure level. ${ }^{[8]}$ Although no standard pressure values have been established, some common practices are accepted. One study recommended a pressure above $15 \mathrm{mmHg}{ }^{[8]}$
Rose and Deitch ${ }^{[12]}$ reported that the most important factor in determining the effectiveness of pressure therapy is the anatomical area treated. In general, the clinical response is positively correlated with higher pressure generated. ${ }^{[8]}$ However, different pressures are generated by conventional pressure garments at different anatomical sites. Therefore, to achieve better pressure effectiveness, pressure garments, or the other pressure methods used, should be improved.

Anatomical concavity is the most important factor in the reduction of the pressure applied by garments. Therefore, conventional garment pressure therapy is seldom effective in the treatment of chest wall keloids, and its usage is limited. We have previously observed many recurrences in patients with chest wall keloids that were treated with conventional pressure therapy [Figures 4 and 5]. Anatomical convexity increases the garment pressure; therefore, methods that can convert an anatomical concavity to an anatomical convexity will also theoretically change the garment pressure. Our inflatable pressure garment device was designed according to this hypothesis. The concave site on the chest wall was converted into a convex shape by inserting the expander under the garment and inflating it. The convexity and pressure increase can 
be controlled by an inflation device, which permits the generation of a range of pressures from 4.5 to $10 \mathrm{kPa}$ (approximately 40 to $77 \mathrm{mmHg}$ ). These pressures are higher than the 20 to $40 \mathrm{mmHg}$ pressure range that other authors have recommended.

Compared to hypertrophic or normal scars, keloid scars have a higher recurrence potential. A pressure range under $40 \mathrm{mmHg}$ may be effective in treating hypertrophic or normal scars. However, this is not the case in the treatment of keloids, where higher treatment pressures may be necessary. The generated pressure range is limited for conventional pressure garments, which cannot generate suitable pressure levels in specific areas, especially concave sites. The inflatable pressure garment that we designed can generate any anticipated pressure at any specific site. Pressures higher than $40 \mathrm{mmHg}$ at a keloid site can be generated with this device. The pressure generated with this device may be more effective in treating keloids, preventing recurrence and achieving satisfactory clinical results.

Although pressure therapy is effective in scar treatment and prevention, inflatable pressure device can generate more effective therapy pressure, surgical intervention should also be emphasized in keloid treatment especially chest wall keloid treatment. Effective wound tension release should be achieved. Normal wound healing process should be guaranteed. To achieve this, some operation method such as "Z-plasty" and tension line redirection can be used. More satisfactory results would be reached if combined application of the inflatable pressure device with other clever surgical methods.

In conclusion, an inflatable pressure garment can generate appropriate and effective pressure on the chest wall by changing its shape from concave to convex and may be a useful device for preventing keloid recurrence involving the chest wall.

\section{Authors' contributions}

Manuscript's preparation: S. Liu, K.X. Song

Manuscript's review: Y.B. Wang

Concept design: Y.B. Wang

Literature search: S. Liu
Financial support and sponsorship

None.

\section{Conflicts of interest}

There are no conflicts of interest.

\section{Patient consent}

The informed consent have been obtained from the patients.

\section{Ethics approval}

All the treatment procedures are in accordance with the ethics approval of Peking Union Medical College Hospital.

\section{REFERENCES}

1. Ogunbiyi A. Acne keloidalis nuchae: prevalence, impact, and management challenges. Clin Cosmet Investig Dermatol 2016;9:483-9.

2. Khansa I, Harrison B, Janis JE. Evidence-based scar management: how to improve results with technique and technology. Plast Reconstr Surg 2016;138:S165-78.

3. Love PB, Kundu RV. Keloids: an update on medical and surgical treatments. J Drugs Dermatol 2013;12:403-9.

4. Kuribayashi S, Miyashita T, Ozawa Y, Iwano M, Ogawa R, Akaishi S, Dohi T, Hyakusoku H, Kumita S. Post-keloidectomy irradiation using high-dose-rate superficial brachytherapy. J Radiat Res 2011;52:365-8.

5. Ogawa R, Mitsuhashi K, Hyakusoku H, Miyashita T. Postoperative electron-beam irradiation therapy for keloids and hypertrophic scars: retrospective study of 147 cases followed for more than 18 months. Plast Reconstr Surg 2003;111:547-53.

6. Yigit B, Yazar M, Alyanak A, Guven E. A custom-made silicon mold for pressure therapy to ear keloids. Aesthetic Plast Surg 2009;33:849-51.

7. Van den Kerckhove E, Stappaerts K, Fieuws S, Laperre J, Massage P, Flour M, Boeckx W. The assessment of erythema and thickness on burn related scars during pressure garment therapy as a preventive measure for hypertrophic scarring. Burns 2005;31:696-702.

8. Giele H, Liddiard K, Booth K, Wood F. Anatomical variations in pressures generated by pressure garments. Plast Reconstr Surg 1998;101:399-406.

9. Linares HA, Larson DL, Willis-Galstaun BA. Historical notes on the use of pressure in the treatment of hypertrophic scars or keloid. Burns 1993; 19:17-21.

10. Chang LW, Deng WP, Yeong EK, Wu CY, Yeh SW. Pressure effects on the growth of human scar fibroblasts. J Burn Care Res 2008;29:835-41.

11. Tan J, Fu JF. Effects of pressure therapy on the proliferation and apoptosis of cells in hypertrophic scar of burn patients. Zhonghua Shao Shang Za Zhi 2013;29:509-15.

12. Rose MP, Deitch EA. The clinical use of tubular compression bandage, Tubigrip, for burn-scar therapy: a critical analysis. Burns $1985 ; 12: 58-64$. 